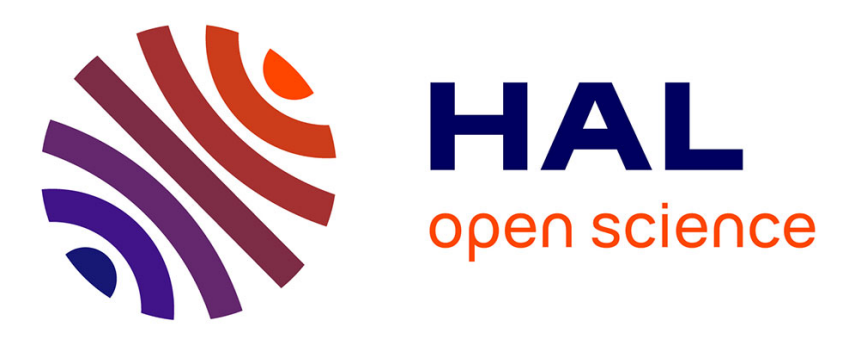

\title{
Population genetic structure of the European kestrel in Central Poland
}

\author{
Robert Rutkowski, Łukasz Rejt, Anna Tereba, Alicja
}

Gryczyńska-Siemiątkowska, Bartosz Janic

\section{- To cite this version:}

Robert Rutkowski, Łukasz Rejt, Anna Tereba, Alicja Gryczyńska-Siemiątkowska, Bartosz Janic. Population genetic structure of the European kestrel in Central Poland. European Journal of Wildlife Research, 2009, 56 (3), pp.297-305. 10.1007/s10344-009-0320-1 . hal-00535251

\section{HAL Id: hal-00535251 \\ https://hal.science/hal-00535251}

Submitted on 11 Nov 2010

HAL is a multi-disciplinary open access archive for the deposit and dissemination of scientific research documents, whether they are published or not. The documents may come from teaching and research institutions in France or abroad, or from public or private research centers.
L'archive ouverte pluridisciplinaire HAL, est destinée au dépôt et à la diffusion de documents scientifiques de niveau recherche, publiés ou non, émanant des établissements d'enseignement et de recherche français ou étrangers, des laboratoires publics ou privés. 


\title{
Population genetic structure of the European kestrel Falco tinnunculus in Central Poland
}

\author{
Robert Rutkowski • Lukasz Rejt • Anna Tereba • \\ Alicja Gryczyńska-Siemiątkowska • Bartosz Janic
}

Received: 23 October 2008 /Revised: 12 August 2009 /Accepted: 26 August 2009/Published online: 16 September 2009

(C) Springer-Verlag 2009

\begin{abstract}
We analysed the genetic structure of the European kestrel population of Central Poland using nine highly polymorphic microsatellite loci. Samples were collected in two urban locations (Warsaw and Łódź) and two rural areas. Sampling locations were at nearly equal distances from each other along an east to west line. We performed genotyping in a total of 99 birds. The results revealed the presence of a genetic structure in the population investigated. Bayesian clustering indicated that samples originated from more than one population. Genetic differentiation was less pronounced among the birds nesting in Warsaw and in the two rural sites, whereas all pairwise comparisons with the Łódź population indicated moderate and significant genetic differentiation. The observed pattern of differentiation might have been caused by two factors: changes in allele frequency between seasons and/ or the founding of the urban population of Łódź from a different source population than the urban population from Warsaw. Additionally, we found a rather high gene flow among kestrels from the Warsaw urban area and the two investigated rural areas.
\end{abstract}

Communicated by W. Lutz

R. Rutkowski $(\bowtie) \cdot$ Ł. Rejt $\cdot$ A. Tereba

Museum and Institute of Zoology, Polish Academy of Sciences,

Wilcza 64

00-679 Warsaw, Poland

e-mail: robertrut@miiz.waw.pl

A. Gryczyńska-Siemiątkowska

Institute of Zoology, Department of Ecology,

University of Warsaw,

Banacha 2,

02-097 Warsaw, Poland

\section{B. Janic}

Department of Ecology and Vertebrate Zoology,

University of Łódź,

Banacha 12/16,

90-237 Lodz, Poland
Keywords Falco tinnunculus · Population genetic Genetic structure $\cdot$ Urban populations $\cdot$ Microsatellites

\section{Introduction}

The majority of animal species exhibit some level of genetic population structuring caused by a variety of factors. Dispersal ability, dietary specialisation, phenological asynchrony, discrete differences in breeding biology and mating systems as well as environmental barriers and the spatial structure of habitat may all influence the genetic structure of populations (e.g. Peterson and Denno 1998; Höglund et al. 1999; Donnelly and Townson 2000; Hendry and Day 2005; Keyghobadi et al. 2005). The processes of anthropogenic changes of natural habitats have, especially recently, led to the artificial fragmentation of many populations. Despite the intensive expansion of urbanised areas, only a few studies, up until now, have investigated the relationship between urban landscapes and population genetic structure (Rubin et al. 2001; Wood and Pullin 2002). These studies demonstrated the effects of isolation and reduced gene flow between habitat fragments within urban areas. However, the genetic relationships between populations of the same species living in urban and rural environments have seldom been studied. Moreover, the majority of these studies were focused on animal species which were trapped in habitat fragments due to urbanisation: small patches of wetland habitats in the case of turtles (Rubin et al. 2001), remnant forest fragments in the case of beetles (Desender et al. 2005) or grassland patches in the case of butterflies (Wood and Pullin 2002), and hence dealt with populations that were isolated by patches of less suitable or unsuitable habitat. Meanwhile, some species actively colonise cities with foxes as one of the best known examples (Gloor et al. 2001; Wandeler et al. 2003). In such 
cases, the influence of the urban environment on the population structure and on the genetic differentiation between groups from urbanised areas and rural habitats may be much more complex. For example, urban areas, as most species are unlikely to be adapted to them, might function as dispersal sinks maintained by constant immigration from rural populations. Hence, source and sink populations may become indistinguishable even if they are partially isolated (Rousset 1999). On the other hand, some groups of individuals may adapt to local urban conditions and resources. Such adaptation may then result in reproductive isolation leading to a pronounced genetic structure strengthened by the effects of the founder event and random genetic drift especially when a colonising group is small (Gloor et al. 2001).

The European kestrel, widely distributed in the Western Palearctic region, lives in different types of habitats, mainly in vast open spaces, but is also commonly observed in urban-industrial environment areas-the species has been present in European cities for more than 150 years (e.g. Village 1990, Śliwa and Rejt 2006). The Polish population of the species is partially migratory, hence, composed of migrants and resident individuals. Despite its relative abundance in the whole country, the kestrel population is rather patchily distributed especially during the breeding season. Birds tend to gather in built-up areas and nest on high buildings or, if accessible, in nesting boxes. In rural regions, tree-based nests have been systematically disappearing over the last few decades. Similarly, observation data suggest that the number of kestrels in many rural areas seems to have decreased in the last decades (Śliwa and Rejt 2006), whereas they appear to become increasingly abundant in cities. It is not clear whether this patchy distribution, caused mainly by gathering within urban areas during breeding season, affects the population genetic structure of the species. However, some level of genetic isolation among urban and rural groups of birds was seen in the Warsaw area (Rejt et al. 2004; Rutkowski et al. 2006).

In Warsaw, the European kestrels have been observed regularly since the $1970 \mathrm{~s}$, and presently their population is estimated at ca. 70 breeding pairs (Rejt 2007). These breeding pairs are evenly distributed across the city-they nest in the centre of Warsaw, as well as in suburban areas, with numerous open spaces and more similar to natural habitat. Observations suggest that these birds exhibit features which are characteristic of the so-called synurbic populations (e.g. Luniak 2004) - they tend to be resident, re-occupy their former nests and start breeding earlier than rural populations (Rejt 2007). In Warsaw, European kestrels produce 4.4-5.4 successfully reared offspring per breeding pair-slightly higher than rural populations (about four successfully reared offspring per breeding pair). The mortality rate of the offspring of urban birds is about $50 \%$ in the first year and increases in subsequent seasons (review in Śliwa and Rejt 2006). In Warsaw, bulk of prey is composed by mammals (mostly voles "Microtus" sp). Their proportion reached more than $85 \%$. Other prey groups were significantly less numerous - birds composed about $12 \%$ of prey; reptiles less than 4\% (e.g. Śliwa and Rejt 2006).

In Łódź, the European kestrel was described as a new breeding species for central parts of the city in the 1980s (Markowski et al. 2004). Kestrel pairs most willingly nest in the strongly urbanised centre of the town and in large industrial complexes. Presently, the population size is estimated at 40-45 pairs (B. Janic, unpublished data).

In this paper, we applied highly polymorphic microsatellite loci to investigate if the patchy distribution of European kestrels across rural and urban (Warsaw and Łódź cities) areas causes a genetic structure in the population of this species.

\section{Materials and methods}

Study area and sample collection

During a 6-year period (2002-2007), we collected material from 99 individuals of the European kestrels from four sampling sites (Fig. 1): an urban area of Warsaw $\left(52^{\circ} 13^{\prime} \mathrm{N} 21^{\circ} \mathrm{E} ; n=44\right)$; an urban and suburban area of Łódź $\left(51^{\circ} 55^{\prime} \mathrm{N} 19^{\circ} 25^{\prime} \mathrm{E} ; n=15\right)$; a rural area near Lowicz town $\left(52^{\circ} 07^{\prime} \mathrm{N} 19^{\circ} 56^{\prime} \mathrm{E}\right)$ about $50 \mathrm{~km}$ east from Łódź and $80 \mathrm{~km}$ west from Warsaw $(n=18)$ and a rural area near Siedlce town $\left(52^{\circ} 13^{\prime} \mathrm{N} 22^{\circ} 16^{\prime} \mathrm{E}\right)$ about $90 \mathrm{~km}$ east from the geographical centre point of Warsaw $(n=22)$.

Blood and feather samples were collected from nestlings. To avoid losses among chicks (resulting from blood loss and/or escaping from nests), all manipulations were done between the 10th and 15th day of their lives according to the Ethic Committee decision No. 157/2002. In the majority of cases, we collected material from two randomly chosen individuals per nest (Table 1).

Blood samples (57.5\% of total sample) were collected and stored on FTA cards (Whatman BioScience). Feathers ( $42.5 \%$ of total sample) were stored dry in Eppendorf tubes. In Warsaw, all nests were situated on buildings. In Łódź, kestrels also nested on buildings or in nesting boxes. In Lowicz, nests were built on top of the roof of a church that was located within the open agricultural environment separated from other build-up areas. Samples from Siedlce were from nesting boxes placed on high trees.

DNA isolation and analysis of microsatellite markers

Deoxyribonucleic acid (DNA) from blood stored on FTA cards was extracted according to the manufacturer's protocol. DNA from feathers was extracted using the QIAamp DNA Mini Kit (Qiagen, Hilden, Germany). Only root ends of feathers, 
Fig. 1 Map of Poland with sampling location (black dots)

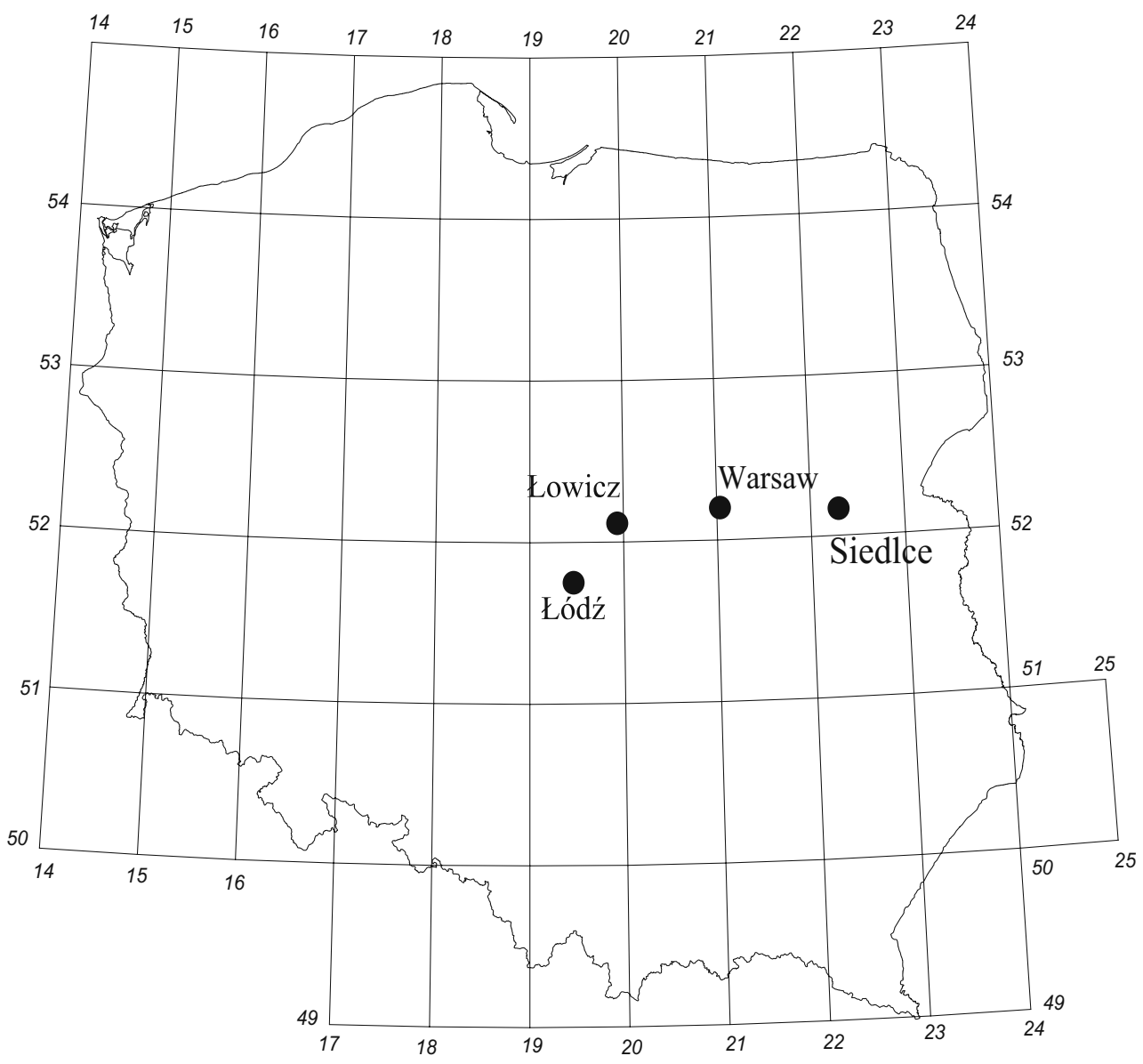

$100 \mathrm{~km}$

approximately $0.5 \mathrm{~cm}$ long, were used for extraction. They were crushed, placed in $180 \mu \mathrm{l}$ of ATL buffer (Qiagen) and incubated at $56^{\circ} \mathrm{C}$ overnight with $20 \mu \mathrm{l}$ of proteinase $\mathrm{K}(20 \mu \mathrm{g} /$ $\mathrm{ml})$. Then, extraction followed the standard protocol. Finally, DNA was eluted in $200 \mu$ of elution buffer (Qiagen).

Table 1 Description of kestrel samples collected for genetic analysis

\begin{tabular}{llllll}
\hline & Łódź & Łowicz & Warsaw & Siedlce & Total \\
\hline$n$ & 15 & 18 & 44 & 22 & 99 \\
$N$ & 9 & 10 & 22 & 11 & 52 \\
$N_{\text {(ii) }}$ & 6 & 8 & 22 & 11 & 47 \\
$N_{\text {(i) }}$ & 3 & 2 & - & - & 5 \\
Years of sampling & & & & & \\
2002 & - & - & 40 & - & 40 \\
2003 & - & - & 4 & - & 4 \\
2004 & - & 4 & - & 10 & 14 \\
2005 & - & 5 & - & 12 & 17 \\
2006 & 15 & 8 & - & - & 23 \\
\hline
\end{tabular}

$n$ number of individuals sampled, $N$ number of nests sampled, $N_{(i i)}$ number of nests where two samples were collected, $N_{(i)}$ number of nests where single samples were collected
By PCR, we amplified nine microsatellite loci as described by Nesje et al. (2000): NVHfp79-4, NVHfp13, NVHfp31, NVHfp5, NVHfp46-1, NVHfp89, NVHfp79-1, NVHfp82-2 and NVHfp86-2. Microsatellite DNA from feathers was amplified in a $25-\mu 1$ reaction mix which contained $10 \mathrm{pmol}$ of each primer, 10-50 $\mathrm{ng}$ of template DNA, $12.5 \mu$ of REDTaq PCR ReadyMix (Sigma-Aldrich) and $7.5 \mu \mathrm{l}$ of PCR-grade water (Sigma-Aldrich). For the microsatellite amplification, from blood DNA, we placed a little piece of blood containing an FTA card (ca. $2 \mathrm{~mm}$ in diameter) into a tube with $30 \mu \mathrm{l}$ of PCR reaction mix, containing $15 \mu \mathrm{l}$ of Red Taq Ready Mix (Sigma-Aldrich), 5 pmol of each primer and $14 \mu \mathrm{l}$ of PCR-grade water (Sigma-Aldrich). Forward primers were 5'-labelled with a fluorescent dye: Dye2, Dye3 or Dye4 (ProOligo). Prior to PCR, all reagents, tubes and pipettes were exposed to ultraviolet light for $15 \mathrm{~min}$. The following PCR profiles were used in a Techne Touchgene thermocycler: initial denaturation for $3 \mathrm{~min}$ at $94^{\circ} \mathrm{C}$, followed by 34 cycles of $1 \mathrm{~min}$ at $94^{\circ} \mathrm{C}, 45 \mathrm{~s}$ at $55^{\circ} \mathrm{C}, 45 \mathrm{~s}$ at $72^{\circ} \mathrm{C}$ and one cycle of $1 \mathrm{~min}$ at $94^{\circ} \mathrm{C}, 45 \mathrm{~s}$ at $55^{\circ} \mathrm{C}$ and $5 \mathrm{~min}$ at $72^{\circ} \mathrm{C}$.

The length of amplified fragments was estimated using a CEQ8000 Beckman Coulter automated sequencer (Beckman 
Coulter, Fullerton, CA, USA). Data were analysed using Beckman Coulter Fragment Analysis Software (v. 9.0).

\section{Statistical analysis}

For each locus and each location investigated, we assessed number of alleles (A), allelic richness (R; Petit et al. 1998), observed heterozygosity $\left(\mathrm{H}_{\mathrm{O}}\right)$ and unbiased expected heterozygosity $\left(\mathrm{H}_{\mathrm{E}}\right.$; Nei and Roychoudhury 1974). The inbreeding fixation index $\left(F_{\mathrm{IS}}\right)$ was calculated for each sampling location, and its significance was tested using 360 randomisations. A Bonferroni correction was applied for multiple comparisons. To assess whether our sampling scheme (sampling of two nestlings from one nest) influences the level of observed heterozygosity and deviation of heterozygosity from values expected under HardyWeinberg equilibrium, we repeated the calculation of $F_{\text {IS }}$ with random sample sets containing only one sample from each nest. For each population, we repeated this random sampling ten times, calculating $F_{\text {IS }}$ for each sample set. These analyses were performed using GenAlEx (v. 5.04; Peakall and Smouse 2001) and FSTAT (v. 2.9.3; Goudet 2001). Genotypic linkage disequilibrium among all pairs of loci was evaluated using Genepop (v.3.1b; Raymond and Rousset 1995). We also applied the software MicroChecker (van Oosterhout et al. 2004) to test for the presence of "null alleles" as well as for possible scoring errors. The latter problem was excluded by the analysis; however, presence of "null alleles" was suggested for some loci in all populations except for loci from the Lódź population (see Results). Thus, we estimated the frequency of these alleles using the algorithm of van Oosterhout et al. (2004), and all subsequent analyses were performed based on corrected genotypes.

Presence of a genetic structure in the kestrel population and pattern of genetic differentiation among different groups of birds was tested using a variety of methods. First, we estimated significance of genotypic differentiation among the investigated groups of birds using Genepop (v.3.1b; Raymond and Rousset 1995). We also estimated measures of population differentiation with pairwise $F_{\mathrm{ST}}$ by using an analysis of molecular variance procedure of the software Arlequin (v. 2.0, Schneider et al. 2000), which calculates $F_{\mathrm{ST}}$ as described by Weir and Cockerham (1984). $P$ values for $F_{\mathrm{ST}}$ were calculated using 1,000 permutations. Then, we used SAMOVA software (v. 1.0; Dupanloup et al. 2002) to estimate the proportion of variance at different levels of population subdivision. The following indices were estimated: $F_{\mathrm{CT}}$, a measure of differentiation between groups of locations; $F_{\mathrm{SC}}$, a measure of sub-structuring within groups and $F_{\mathrm{ST}}$, a measure of differentiation among locations after accounting for regional structure. The significance of the observed variance components was evaluated by means of a non-parametric permutation method.

Then, we estimated Nei's standard genetic distance $D_{\mathrm{S}}$ (Nei 1972) using an online calculator (http://www.biology. ualberta.ca/jbrzusto) and Slatkin's (1995) $R_{\mathrm{ST}}$, an analogue of $F_{\mathrm{ST}}$ developed for analysing microsatellite data using RstCalc (Goodman 1997). To get unbiased estimate of $R_{\mathrm{ST}}$, the data set was standardised for sample size and allelic length, and the variance components were averaged over loci before calculating $R_{\mathrm{ST}}$. $P$ values for $R_{\mathrm{ST}}$ were calculated using 1,000 permutations.

Finally, we used the Bayesian clustering method (Structure v. 2; Pritchard et al. 2000) to examine how well predefined "populations" (=sampling locations) corresponded to genetic groups $(K)$. To choose an appropriate run length, we performed ten runs for each value of $K$ with different values of burn-in and run length (from 10,000 to $1,000,000)$. Results of these initial simulations were checked for variation across runs for each value of $K$ to assess contingency across simulation. We found that the likelihoods have converged at burn-in of 50,000 and 100,000 iterations of the total data set. Thus, we performed additional three runs for each user-defined $K(1-4)$ with an initial burn-in of 50,000 and 100,000 iterations. Default values were maintained for all other parameters. We used the admixture model of ancestry and the correlated model of allele frequencies. The proportion of membership of each predefined "population" within each genetic group was estimated for $K$ with the highest likelihood. Sampling location was not used as prior information.

Although reliable estimate of a significant association between geographical and genetic distances requires comparison of at least five populations, we decided to perform Mantel test to check whether there is any suggestion of isolation by distance among populations investigated. This analysis was performed with Genepop v.3.1b using the pairwise $F_{\mathrm{ST}}$ as a measure of genetic differentiation between groups.

\section{Results}

We successfully amplified nine microsatellite loci in 95 samples. We failed to amplify NVHfp79-1 in four individuals from Siedlce. All loci analysed were polymorphic with numbers of alleles ranging from five (NVHfp82-2 and NVHfp79-1) to 14 (NVHfp79-4) (Table 2). The test for significance of linkage disequilibrium over all the loci and locations, as well as for each sampling location separately, showed no significant linkage disequilibrium among loci. In general, diversity indices, which were based on microsatellite polymorphisms, showed similar values in the locations investigated (Table 2). The mean value of $\mathrm{A}$ 
across all loci was the highest in Warsaw, but it was caused by a high number of alleles in just one locus - NVHfp46-1. After correction for sample size, allelic richness (R) was the highest in Siedlce. In the locations, except Łódź, $F_{\text {IS }}$ was significantly greater than zero, which indicates heterozygote deficiency. In the analysis of random sample sets containing only one sample from each nest, the same three locations showed $F_{\text {IS }}$ values greater than zero; however, the differences were not statistically significant after Bonferroni correction (Table 2). In one case (Siedlce), the mean $F_{\text {IS }}$ value estimated for the group with one sample per nest $(n=$ 11) was even greater than the one estimated for the group with two samples per nest (Table 2). The global test for heterozygote deficiency also showed significant deviation $(P<0.0001)$ even after an analysis of a data set containing only one randomly chosen sample per nest.

Analysis in Micro-Checker indicated no scoring errors but indicated the presence of "null alleles" in all populations investigated except that in Łódź. In Łowicz, "null alleles" were present in loci NVHfp13 and NVHfp86-2 (frequency 0.23 and 0.17 , respectively; $P<0.05$ ), and in Warsaw in loci NVHfp13 (frequency 0.18), NVHfp5 (0.09), NVHfp46-1 (0.22) and NVHfp86-2 $(0.13 ; P<0.05$ for all these loci). In Siedlce, presence of "null allele" was indicated only for locus NVHfp79-1 (frequency $0.27, P<$ $0.01)$. There was no relation between presence of "null alleles" and sample type (feathers vs. blood samples). For example, Micro-Checker suggested presence of "null alleles" in loci NVHfp13 and NVHfp86-2 in Łowicz and Warsaw, whereas in the former, feathers had been used as a source of DNA, and in the latter, blood stored on FTA cards. Using Micro-Checker, we generated corrected genotypes for each locus with "null alleles", which were subsequently used in analysis of population differentiation.

Genotypic differentiation was significant for all the comparisons among locations (Table 3). Small but significant differentiation among locations was indicated by an overall $F_{\mathrm{ST}}$ value of $0.058(P<0.001)$. Significant values of $F_{\mathrm{ST}}$ were observed for all pairwise comparisons except

Table $3 P$ values for genotypic differentiation (above diagonal) and pairwise comparison of $F_{\mathrm{ST}}$ values (below diagonal) between the sampling localities

\begin{tabular}{lllll}
\hline & Lódź & Lowicz & Warsaw & Siedlce \\
\hline Łódź & & 0.0001 & 0.0001 & 0.0001 \\
Lowicz & 0.1280 & & 0.0096 & 0.00034 \\
Warsaw & 0.1252 & 0.0133 & & 0.00010 \\
Siedlce & 0.1177 & 0.0488 & 0.0232 & \\
\hline
\end{tabular}

Italicized values of $F_{\mathrm{ST}}$ are significant after Bonferroni correction (corrected $P=0.00833$ ) 
Warsaw-Lowicz. For all comparisons with Łódź, $F_{\mathrm{ST}}$ suggested moderate genetic differentiation (Table 3), whereas values for comparison among Warsaw, Łowicz and Siedlce indicated small genetic differentiation. Similarly, SAMOVA indicated the only significant $F_{\mathrm{CT}}$ when populations were grouped into two groups (group 1, Łódź; group 2, Łowicz, Warsaw and Siedlce; $F_{\mathrm{CT}}=0.10669, P<$ $0.0001 ; \quad F_{\mathrm{SC}}=0.02926, P<0.0001 ; \quad F_{\mathrm{ST}}=0.13282, P<$ $0.0001)$. More than $10 \%$ of the genetic variation was explained by differentiation between groups of populations; $1.7 \%$ by variation among populations within groups and nearly $88 \%$ by within-population variation.

Pairwise Nei's standard genetic distance and $R_{\mathrm{ST}}$ showed a pattern similar to $F_{\mathrm{ST}}$ values. In both cases, the smallest value was observed between Warsaw and Lowicz, whereas the highest values were observed for pairwise comparisons with Łódź (Table 4). Overall $R_{\mathrm{ST}}$ was $0.167 \quad(P<0.001)$ indicating moderate and significant population structure.

The Bayesian analysis in structure revealed the highest posterior probability for three genetic clusters under admixture model [mean value for three runs $\ln P(X \mid K)=$ -2707.16; $P(K \mid X) \approx 0.99$ ]. Cluster I was nearly exclusively composed by individuals from Łódź: 14 of individuals from this locality were assigned to this cluster, whereas one was assigned to cluster II and another one to cluster III. Cluster II and III were composed of individuals from Łowicz, Warsaw and Siedlce, symmetrically distributed between those two clusters (Fig. 2).

Mantel test revealed that $F_{\mathrm{ST}}$ pairwise comparisons were not related to geographical distance $(r=0.34 ; P=0.1)$. However, after the exclusion of the Łódź population, correlation was stronger but still insignificant $(r=0.87 ; P=0.09)$.

\section{Discussion}

Until now, at least three different processes have been described to cause population genetic structure in kestrels. The first one is spatial separation as demonstrated in kestrels from the Cape Verde archipelago (Hille et al. 2003). There, a genetic structure evolved through spatial isolation by water belts, and genetic differentiation was

Table 4 Nei's standard genetic distance $D_{\mathrm{S}}$ (above diagonal) and $R_{\mathrm{ST}}$ (below diagonal) among the sampling localities

\begin{tabular}{lllll}
\hline & Lódź & Łowicz & Warsaw & Siedlce \\
\hline Łódź & & 0.367 & 0.389 & 0.384 \\
Lowicz & 0.2208 & & 0.061 & 0.140 \\
Warsaw & 0.1869 & 0.0120 & & 0.088 \\
Siedlce & 0.1863 & 0.1084 & 0.0477 & \\
\hline
\end{tabular}

Italicized values of $R_{\mathrm{ST}}$ are significant $(P<0.05)$ correlated with geographical distances among islands. The second one is breeding asynchrony, which generates genetic differentiation between early- and late-breeding groups of kestrels even within a sympatric population (Casagrande et al. 2006). The third process is a reduced gene flow between birds nesting in urban and rural environments (Rutkowski et al. 2006); however, this observation should be considered as preliminary. The results suggested the presence of a genetic structure in the population, and different measures of genetic distance show a very similar pattern of differentiation among populations. However, we did not find any clear pattern of differentiation between urban and rural populations. All pairwise measures of genetic differentiation, as well as Bayesian clustering and SAMOVA, clearly indicated the presence of two groups of birds. The first group contained kestrels from the urban area of Warsaw and two adjacent rural areas, whereas the second group was composed of birds from the urban area of Łódź. This pattern could be an outcome of our sampling scheme: samples from Łódź were collected during a single season separated by 4 years from the season in which the majority of samples from Warsaw were collected. The mean lifespan of kestrels, based on ringing data, was assessed to be 1.31.9 years, but for birds in the second year of life, it increases to 2.9 years (reviewed in Śliwa and Rejt 2006). Most kestrels breed for the first time in their first year of life (Village 1990, 1998). However, among breeders, the proportion of first-year breeders may vary between $60 \%$ and $6 \%$ depending on the phase of vole cycle or seasonal migration (e.g. Village 1998; Laaksonen et al. 2004). Hence, in the case of kestrel, the shift in allele frequencies among seasons can be considerable. On the other hand, we found a rather small differentiation between the Warsaw and Łowicz populations despite sampling of these populations in different years, whereas both of them showed an almost identical value of $F_{\mathrm{ST}}$ in comparison with Łódź. This suggests that changes in allele frequencies among seasons may not be very significant. For example, philopatry could prevent such changes. Unfortunately, there is no precise data on the level of philopatry in the populations studied. In other rural kestrel populations, the philopatry seems to be low but varies simultaneously with the varying abundance of voles: in Fennoscandia, only $8 \%$ of the females and about $25 \%$ of the males return to their breeding territories the following year (Lundvall 1996) while in Holland, between $10 \%$ and $70 \%$ of birds do return according to the vole index (Cave 1968). Ringing data from Berlin suggests that birds, which had hatched in urban areas, tend to return to their sites of birth (S. Kupko, unpublished data). Nonetheless, this issue requires further investigation especially the comparison of samples from different populations collected in one season as well as among different seasons in separate populations. 


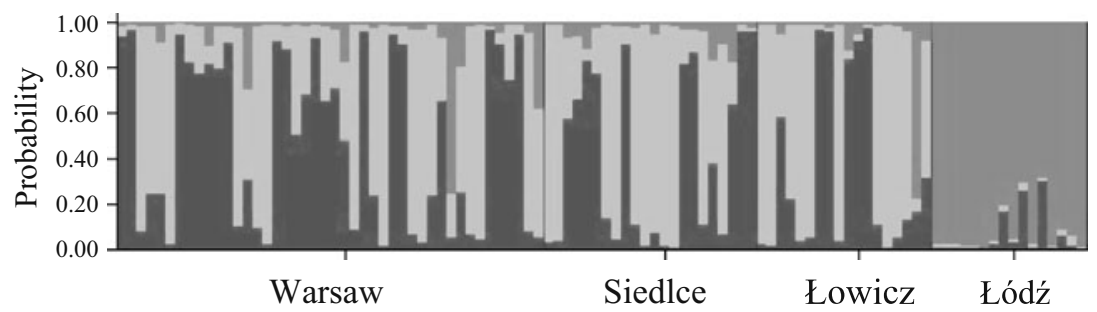

Fig. 2 Bayesian assignment of individuals to $K=3$ clusters without using prior population information. Each bar represents the estimated posterior probability of each individual bird belonging to

Differentiation between the two investigated urban areas could also be explained by another factor. It is possible that the urban populations in Łódź and Warsaw were formed by different groups of individuals. Then, founder effect and subsequent genetic drift could generate significant genetic differentiation between them. Indeed, the urban populations of Łódź and Warsaw differ in some aspects. For example, the first breeding pairs were observed (in the centre of Łódź) in 1980 (B. Janic, unpublished data), whereas in Warsaw, kestrels have been regularly observed since the 1970 s, and the number of pairs breeding within city borders is now much higher than in Łódź (Rejt 2007).

Genetic structure within the group of the other three localities, Łowicz, Warsaw and Siedlce, was weakly pronounced, and pairwise measures of genetic differentiation indicated the presence of intensive gene flow between localities. This group of localities is a rather panmictic unit irrespective of the presence of the urban environment, and genes are frequently exchanged between the city and adjacent areas. This fact stands in contradiction with results obtained for the urban populations of other species. In their study of the fox population living in the city of Zurich and in adjacent rural areas, Wandeler et al. (2003) found significant genetic differentiation between rural and urban groups - pairwise comparisons among rural sampling sites showed no genetic differentiation (estimated by $F$ statistics), whereas differentiation among the urban and rural groups was high and significant. Unfortunately, there are few similar studies on birds, which are much more mobile and thus able to cross natural and artificial barriers better than mammals. However, in the case of European blackbird (Turdus merula), analysis of neutral genetic markers showed no genetic differentiation between urban and a nearby forest-living population (Partecke et al. 2006) despite several phenotypic differences between these populations (Partecke 2003; Partecke et al. 2004). Although the study is based on small number of individuals and only two populations, this result suggests that high mobility create favourable conditions for intensive gene flow between urban and rural populations of birds.

Differentiation between the Lowicz rural area and the Warsaw urban area was small and insignificant suggesting each of the inferred clusters. Dark grey cluster I, light grey cluster II, black cluster III. Solid black lines define the boundaries between the four sampled populations

strong gene flow. In the case of Łowicz, since samples were collected from nests placed on a building, this group may represent birds which "prefer" urban landscapes (i.e. buildings); it may even consist of migrants from the urban area of Warsaw. A similar phenomenon was found for the Peregrine-young birds released from cliff-like sites (e.g. buildings) also preferred them as nesting places later on (Kirmse 2001). For the time being, our data are too weak to confirm or reject such a pattern for kestrels. Additionally, a large number of samples from birds nesting on buildings, in nesting boxes and in high trees are required in order to analyse whether the selection of nesting sites could influence the genetic structure of the species.

In three out of the four localities investigated, we have found heterozygote deficiency, which could be due to the presence of "null alleles", at least at some loci. However, other explanations are also possible. A similar phenomenon was found by Hille et al. (2003) in a kestrel population from Austria. Authors ascribed this observation to polygamy, which was known to exist in that population. In kestrels, polgyny reaches $12 \%$ and is probably associated with colonial breeding (Glutz von Blotzheim 1971; Village 1998). In seasons with a high vole number, it may even reach 20\% (Korpimäki et al. 1996). The level of polyandry in open landscape populations is usually only $5-7 \%$ but could be lower in years with poor prey abundance (Village 1990). In addition, frequency of extra-pair fertilisations among birds of prey increases with the growing density of breeding pairs (Korpimäki et al. 1996; Mougeot 2000), and increased density of breeding pairs is thought to be one of the factors connected with synurbisation (Luniak 2004). Indeed, observation of ringed birds in Warsaw provides evidence that some females copulate with more than one male during single breeding season (Rejt $\ell$, personal observation). Thus, extra-pair fertilisation could be a possible explanation for the significant heterozygote deficiency in the case of the Warsaw but only if small number of males would participate in the reproduction of a whole population. It is also possible that a similar process took place in the Lowicz group where a few nests were found on one building. Hence, the presence of buildings within the environment changes the nesting behaviour of kestrels may be not only in terms of 
nesting site selection but also in terms of nesting-related territorial behaviour, which can favour extra-pair copulation and paternity. On the other hand, an $F_{\text {IS }}$ value significantly greater than zero was found in Siedlce where the density of nesting pairs did not change.

Another explanation of homozygote excess could be inbreeding within the population. Although such a process is usually the case for small, isolated populations, some plumage aberrations were observed in kestrels from Warsaw (Rejt 2004). Based on the present data, it is difficult to judge if such aberrations and significant $F_{\text {IS }}$ values are really effects of inbreeding. However, if strong philopatry existed in urban populations, it is possible that breeding could occur between closely related individuals resulting in an increase in homozygosity.

Acknowledgements The study was partly supported by the Ministry of Science and Higher Education grant no. N N304 4078 33. We thank all persons who contributed in the gathering of material for genetic analysis. We also thank two anonymous reviewers for valuable and constructive comments on the paper.

The experiment presented in this paper complies with the current laws of Poland.

\section{References}

Casagrande S, Dell'Omo G, Costantini D, Taglivini J (2006) Genetic differences between early- and late-breeding Eurasian kestrels. Evol Ecol Res 8:1029-1038

Cave AJ (1968) The breeding of the kestrels, Falco tinnunculus L., in the reclaimed area Oostelijk Flevoland. Netherlands J Zool 18:313-407

Desender K, Small E, Gaublomme E, Verdyck P (2005) Rural-urban gradients and the population genetic structure of woodland ground beetles. Conserv Genetics 6:51-62

Donnelly MJ, Townson H (2000) Evidence for extensive genetic differentiation among populations of the malaria vector Anopheles arabiensis in Eastern Africa. Insect Mol Biol 9:357-367

Dupanloup I, Schneider S, Excoffier L (2002) A simulated annealing approach to define the genetic structure of populations. Mol Ecol 11:2571-2581

Gloor S, Bontadina F, Hegglin D, Deplazes P, Breitenmoser U (2001) The rise of urban fox populations in Switzerland. Mamm Biol 66:155-164

Glutz von Blotzheim UN (ed) (1971) Handbuch der Voegel Mitteleeuropas T. 4. Falconiformes. Akademische Verlagsgesellschaft, Frankfurt/Main

Goodman SJ (1997) RstCalc: a collection of computer programs for calculating estimates of genetic differentiation from microsatellite data and determining their significance. Mol Ecol 6:881-885

Goudet J (2001) FSTAT V2.9.3, a program to estimate and test gene diversities and fixation indices. http://www.unil.ch/izea/ softwares/fstat.htlm. Accessed Feb 2002

Hendry AP, Day T (2005) Population structure attributable to reproductive date: isolation-by-time and adaptation-by-time. Mol Ecol 14:901-916

Hille SM, Nesje M, Segelbacher G (2003) Genetic structure of kestrel populations and colonization of the Cape Verde archipelago. Mol Ecol 12:2145-2151
Höglund J, Alatalo RV, Lundberg A, Rintamaki PT, Lindell J (1999) Microsatellite markers reveal the potential for kin selection on black grouse leks. Proc R Soc Lond B 266:813-816

Keyghobadi N, Roland J, Strobeck C (2005) Genetic differentiation and gene flow among populations of the alpine butterfly, Parnasisus smintheus, vary with landscape connectivity. Mol Ecol 14:1897-1909

Kirmse W (2001) Wiedereinbürgerung baumbrütender Wanderfalken (Falco peregrinus) in Mitteleuropa. Z Jagdwiss 47:165-177

Korpimäki E, Lahti K, May CA, Parkin DT, Powell GB, Tolonen P, Wetton JH (1996) Copulatory behaviour and paternity determined by DNA fingerprinting in kestrels: effects of cyclic food abundance. Anim Behav 51:945-955

Laaksonen T, Lyytinen S, Korpimäki E (2004) Sex-specific recruitment and brood sex ratios of Eurasian kestrels in a seasonally and annually fluctuating northern environment. Evol Ecol 18:215-230

Lundvall P (1996) Mating and hunting behaviour in European kestrels (Falco tinnunculus). Ph.D. thesis. Ann. Univ. Turkuensis, Ser. A II., Vol. 86, Turku

Luniak M (2004) Synurbization - adaptation of animal wildlife to urban development. In: Shaw WW, Harris LK, VanDruff L (eds) Proceedings of the 4th International Symposium Urban Wildlife Conservation, University of Tucson, Arizona, 1-5 May 1999

Markowski J., Kowalczyk J. K., Janiszewski T., Wojciechowski Z., Szczepko K., Domanski J (2004) Fauna of Lodz-the state of knowledge, changes, protected and threatened species. In: Indykiewicz P., Barczak T. (eds.). Urban fauna of Central Europe in the 21st century. Wydawnictwo Logo, Bydgoszcz (Poland), 19-36 pp. [in Polish]

Mougeot F (2000) Territorial intrusions and copulation patterns in red kites, Milvus milvus, in relation to breeding density. Anim Behav 59:633-642

Nei M (1972) Genetic distance between populations. Am Nat 106:283-292

Nei M, Roychoudhury AK (1974) Sampling variances of heterozygosity and genetic distance. Genetics 76:379-390

Nesje M, Roed KH, Lifjeld JT, Lindberg P, Steen OF (2000) Genetic relationships in the peregrine falcon (Falco peregrinus) analysed by microsatellite DNA markers. Mol Ecol 9:53-60

Partecke J (2003) Annual cycles of urban and forest-living European blackbirds (Turdus merula): genetic differences or phenotypic plasticity? Dissertation at the Ludwig-Maximilians-University, Munich

Partecke J, Van't Hof T, Gwinner E (2004) Differences in the timing of reproduction between urban and forest European blackbirds (Turdus merula): results of phenotypic flexibility or genetic differences? Proc R Soc Lond B 271:1995-2001

Partecke J, Gwinner E, Bensch S (2006) Is urbanisation of European blackbirds (Turdus merula) associated with genetic differentiation? J Ornithol 147:549-552

Peakall R, Smouse PE (2001) GenAlEx V5: Genetic Analysis in Excel. Population genetic software for teaching and research. http://www.anu.ed.au/BoZo/GenAlEx/. Accessed June 2003

Peterson MA, Denno RF (1998) The influence of dispersal and diet breadth on patterns of genetic isolation by distance in phytophagous insects. Am Nat 152:428-446

Petit RJ, el Mousadik A, Pons O (1998) Identifying populations for conservation on the basis of genetic markers. Conserv Biol $12: 844-855$

Pritchard JK, Stephens M, Donnelly P (2000) Inference of population structure using multilocus genotype data. Genetics 155:945-959

Raymond M, Rousset F (1995) GENEPOP (version 1.2): population genetics software for exact tests and ecumenicism. J Hered $86: 248-249$

Rejt $Ł$ (2004) Nietypowe ubarwienie pisklą pustułki Falco tinnunculus w Warszawie. Notatki Ornitologiczne 45:59-61 
Rejt $Ł$ (2007) Breeding biology of urban Kestrel Falco tinnunculus in Warsaw. PhD thesis, Museum and Institute of Zoology, Polish Academy of Sciences, Warsaw [in Polish]

Rejt Ł, Rutkowski R, Gryczyńska-Siemiątkowska A (2004) Genetic variability of urban kestrels in Warsaw-preliminary data. Zoologica Poloniae 49:199-209

Rousset F (1999) Genetic differentiation within and between two habitats. Genetics 151:397-407

Rubin CS, Warner RE, Bouzat JL, Paige KN (2001) Population genetic structure of Blanding's turtles (Emydoidea blandingii) in an urban landscape. Biol Conserv 99:323-330

Rutkowski R, Rejt Ł, Szczuka A (2006) Analysis of microsatellite polymorphism and genetic differentiation in urban and rural kestrels Falco tinnunculus (L.). Pol J Ecol 54:473-480

Schneider S, Roessli D, Excoffier L (2000) ARLEQUIN: a software for population genetic data analysis, ver. 2.000. University of Geneva, Geneva
Slatkin M (1995) A measure of population subdivision based on microsatellite allele frequencies. Genetics 139:457-462

Śliwa P, Rejt Ł (2006) Kestrel. Wyd. Klubu Przyrodników, Świebodzin [in Polish]

van Oosterhout C, Hutchinson WF, Wills DP, Shipley P (2004) Microchecker: software for identifying and correcting genotyping errors in microsatellite data. Mol Ecol Notes 4:535-538

Village A (1990) The kestrel. Poyser, London

Village A (1998) Kestrel. BWP Update 2:121-136

Wandeler P, Funk M, Largiader R, Gloor S, Breitenmoser U (2003) The city-fox phenomenon: genetic consequences of a recent colonization of urban habitat. Mol Ecol 12:647-656

Weir BS, Cockerham CC (1984) Estimating F-statistics for the analysis of population structure. Evolution 38:1358-1370

Wood BC, Pullin AS (2002) Persistence of species in a fragmented urban landscape: the importance of dispersal ability and habitat availability for grassland butterflies. Biodiversity Conserv 11:1451-1468 